\title{
Assessment of myocardial oxygenation in patients with severe aortic stenosis before and after aortic valve replacement: an oxygenation-sensitive CMR study
}

\author{
Masliza Mahmod ${ }^{1 *}$, Jane M Francis ${ }^{1}$, Nikhil Pal ${ }^{1}$, Andrew Lewis ${ }^{1}$, Sairia Dass' ${ }^{1}$, Ravi De Silva², Mario Petrou², \\ Rana Sayeed², Stephen Westaby², Matthew D Robson', Houman Ashrafian', Stefan Neubauer', \\ Theodoros D Karamitsos ${ }^{1}$
}

From 17th Annual SCMR Scientific Sessions

New Orleans, LA, USA. 16-19 January 2014

\section{Background}

Left ventricular hypertrophy in aortic stenosis (AS) is characterised by reduced myocardial perfusion reserve due to coronary microvascular dysfunction. However, it remains unclear whether the hypoperfusion seen in severe AS leads to myocardial tissue deoxygenation and thus, ischemia during stress. The aim of this study was to assess myocardial oxygenation and perfusion in patients with severe AS but no obstructive coronary artery disease before and after aortic valve replacement (AVR).

\section{Methods \\ Twenty two patients with isolated severe AS and unob- structed epicardial coronary arteries on invasive coronary angiography planned to undergo AVR were prospectively recruited. All patients underwent cardiovascular magnetic resonance (CMR) at 3 Tesla. Myocardial function, perfu- sion (myocardial perfusion reserve index - MPRI) and oxygenation (blood-oxygen level dependent-BOLD signal intensity - SI change) during adenosine stress and rest, and fibrosis (late gadolinium enhancement - LGE) were assessed. Of the 22 patients who had AVR, 10 of them were rescanned at $8.0 \pm 2.1$ months after AVR. Fifteen age- and gender-matched healthy volunteers served as controls.}

'Oxford Centre for Clinical Magnetic Resonance Research, Division of Cardiovascular Medicine, Radcliffe Department of Medicine, Oxford, UK Full list of author information is available at the end of the article

\section{Results}

Clinical characteristics and CMR are presented in Table 1. All subjects were matched for age, gender and body mass index. AS patients had reduced perfusion reserve (MPRI $1.0 \pm 0.3$ vs. controls $1.7 \pm 0.3, \mathrm{p}<0.001$ ) and blunted oxygenation response during stress (BOLD SI change $4.8 \pm 9.6 \%$ vs. controls $18.2 \pm 11.6 \%, \mathrm{p}=0.001$ ). Myocardial perfusion and oxygenation showed a positive correlation $(\mathrm{R}=0.48, \mathrm{p}=0.005)$. Both MPRI and BOLD had an inverse correlation with maximal left ventricular (LV) wall thickness, $\mathrm{R}=-0.71, \mathrm{p}<0.001$ and $\mathrm{R}=-0.46$, $\mathrm{p}=0.005$, respectively. Myocardial perfusion $(\mathrm{R}=-0.42$, $\mathrm{p}=0.02)$ but not oxygenation $(\mathrm{R}=-0.4, \mathrm{p}=0.06)$ significantly correlated with myocardial fibrosis, respectively. There was significant regression of LVH after AVR (LVMI from $100 \pm 36 \mathrm{~g} / \mathrm{m} 2$ to $71 \pm 19 \mathrm{~g} / \mathrm{m} 2$ and $\mathrm{LV}$ wall thickness from $16 \pm 2 \mathrm{~mm}$ to $14 \pm 2 \mathrm{~mm}$ ) although LVMI and LV wall thickness were still significantly higher compared to normal controls ( $<<0.05$ vs. pre AVR and $\mathrm{p}<0.05$ vs. controls). Importantly, there was substantial improvement in perfusion and oxygenation towards normal after AVR, MPRI $1.5 \pm 0.4, \mathrm{p}=0.005$ vs. $1.1 \pm 0.4$ pre AVR and BOLD SI change $16.4 \pm 7.0 \%$, $\mathrm{p}=0.014$ vs. $4.9 \pm 8.4 \%$ pre AVR (Figure 1 ).

\section{Conclusions}

In severe AS without epicardial CAD, there is blunted oxygenation response to adenosine stress suggestive of microvascular impairment. Myocardial perfusion and oxygenation are restored following AVR. Oxygenation- 
Table 1 Baseline clinical and CMR findings

\begin{tabular}{|c|c|c|c|}
\hline & Severe AS $(n=22)$ & Normal controls $(n=15)$ & $P$ value \\
\hline Age (years) & $67 \pm 9$ & $63 \pm 4$ & 0.09 \\
\hline Male, n (\%) & $15(68)$ & $8(53)$ & 0.34 \\
\hline Body mass index $(\mathrm{kg} / \mathrm{m} 2)$ & $27 \pm 4$ & $26 \pm 3$ & 0.38 \\
\hline BOLD signal intensity change (\%) & $4.8 \pm 9.6$ & $18.2 \pm 11.6$ & 0.001 \\
\hline Myocardial perfusion reserve index & $1.0 \pm 0.3$ & $1.7 \pm 0.3$ & $<0.001$ \\
\hline Left ventricular ejection fraction (\%) & $74 \pm 6$ & $69 \pm 4$ & 0.01 \\
\hline Left ventricular end-diastolic volume (ml) & $148 \pm 46$ & $142 \pm 32$ & 0.65 \\
\hline Left ventricular end-systolic volume (ml) & $40 \pm 20$ & $44 \pm 12$ & 0.43 \\
\hline Left ventricular wall thickness (mm) & $17 \pm 3$ & $10 \pm 1$ & $<0.001$ \\
\hline Left ventricular mass index $(\mathrm{g} / \mathrm{m} 2)$ & $99 \pm 38$ & $56 \pm 13$ & $<0.001$ \\
\hline Aortic valve area $(\mathrm{cm} 2)$ & $0.84 \pm 0.10$ & - & - \\
\hline LGE present, n (\%) & $16(73)$ & $0(0)$ & - \\
\hline LGE volume when positive (\%) & $17.6 \pm 13.8$ & - & - \\
\hline
\end{tabular}

Values are mean SD or percentages. BOLD, blood oxygen level dependent; LGE, late gadolinium enhancement.

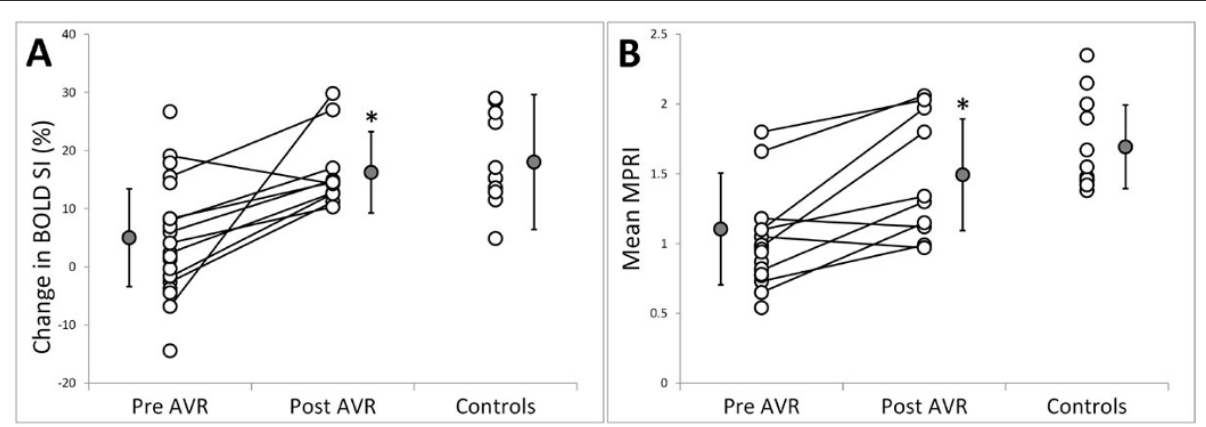

Figure 1 BOLD SI Change and MPRI before and after AVR.

sensitive CMR provides pathophysiologic insight, may become a helpful diagnostic tool, and suggests novel strategies for therapy in AS aimed at improving the oxygen demand/supply balance.

\section{Funding}

None.

\section{Authors' details}

'Oxford Centre for Clinical Magnetic Resonance Research, Division of Cardiovascular Medicine, Radcliffe Department of Medicine, Oxford, UK. ${ }^{2}$ Department of Cardiothoracic Surgery, Oxford University Hospitals, Oxford, UK.

Published: 16 January 2014

doi:10.1186/1532-429X-16-S1-M12

Cite this article as: Mahmod et al:: Assessment of myocardial oxygenation in patients with severe aortic stenosis before and after aortic valve replacement: an oxygenation-sensitive CMR study. Journal of Cardiovascular Magnetic Resonance 2014 16(Suppl 1):M12.
Submit your next manuscript to BioMed Central and take full advantage of:

- Convenient online submission

- Thorough peer review

- No space constraints or color figure charges

- Immediate publication on acceptance

- Inclusion in PubMed, CAS, Scopus and Google Scholar

- Research which is freely available for redistribution

Submit your manuscript at www.biomedcentral.com/submit 